\title{
Effect of etch-and-rinse and self-etching adhesive systems on hardness uniformity of resin cements after glass fiber post cementation
}

Fernanda Zander Grande da Cruz ${ }^{1}$

Christiana Zander Grande ${ }^{1}$

Douglas Augusto Roderjan'

César Augusto Galvão Arrais²

Adriana Postiglione Bührer Samra'

Abraham Lincoln Calixto ${ }^{1}$

\section{ABSTRACT}

Objective: To evaluate the effects of etch-and-rinse and self-etching adhesive systems on Vickers hardness (VHN) uniformity of dual-cured resin cements after fiber post cementation.

Methods: Fifty glass fiber posts were cemented into bovine roots using the following cementing systems: Prime\&Bond 2.1 Dual Cure and Enforce with light-activation (PBDC-LCEN); Prime\&Bond 2.1 and Enforce with light-activation (PB-CLEN); Prime\&Bond 2.1 Dual Cure and Enforce without light exposure (PBDC-SCEN); ED Primer and Panavia 21 (ED-SCPN); and Clearfil SE Bond and Panavia 21 (CF-SCPN). The roots were stored in distilled water for $72 \mathrm{~h}$ and transversely sectioned into thirds (coronal, medium, and apical). The VHN values of the resin cement layers were measured close to the post and to the dentin wall on the transversely sectioned flat surfaces. The results were analyzed by three-way repeated measures analysis of variance (ANOVA) and Tukey's post-hoc test (pre-set alpha of 5\%).

Results: Most resin cements presented higher VHN values near the post than near the dentin wall. The ED-SCPN group showed the highest VHN values regardless of the root third, while the selfcured group PBDC-SCEN exhibited the lowest values. The resin cements from the light-activated groups PBDC-LCEN and PB-LCEN showed lower VHN values at the apical third than at the coronal third. The VHN values were not influenced by the root third in self-cured groups PBDC-SCEN, EDSCPN, and ED-SCPN.

Conclusion: Depending on the product, bonding agents might promote changes in hardness uniformity of resin cements after post cementation. (Eur J Dent 2012;6:248-254)

Key words: Resin cements; microhardness; fiber-glass posts

1 Department of Restorative Dentistry, State University of Ponta Grossa, Ponta Grossa, PR, BRAZIL

2 Department of Operative Dentistry, Guarulhos University, Prça Tereza Cristina, 229, Guarulhos, SP, 07023-070, BRAZIL
Corresponding author: Dr. Abraham Lincoln Calixto Department of Restorative Dentistry, State University of Ponta Grossa, Ponta Grossa, PR, BRAZIL Tel: +55 4232238233 Email: alcalixto@ig.com.br 


\section{INTRODUCTION}

Pre-fabricated posts, such as metallic, carbon and fiber posts, are the first choice for restorative procedures of endodontically treated anterior teeth with severe damage. Among the advantages of fiber posts over the other posts, the most important ones are the esthetics, translucence, and reliable mechanical properties, such as dentin-like elastic modulus. ${ }^{1}$ The post translucence allows light from the curing unit to penetrate through the post to reach and polymerize the surrounding bonding material, promoting adhesion of the cementing system to the root dentin walls. ${ }^{2}$ In contrast to cast posts, pre-fabricated posts require only direct procedures for cementation, and because of their ease of use, no more than one clinical session is required to cement such posts.

Resin cements have been extensively used in restorative dentistry as they are the best choice to bond porcelain, indirect resin laminated veneers, and aesthetic glass or carbon fiber posts to teeth. ${ }^{3}$ Three different types of resin cements are available with regard to their activation modes: chemically cured (self-polymerization), light- and dual-cured (association between auto and light activation) resin cements. Dual-cured resin cements combine the advantages of light- and self-polymerized resin cements as photoinitiators, tertiary amines, and self-curing components are added to their composition to allow polymerization to start even when the curing light is severely attenuated or blocked by the presence of an indirect restoration. ${ }^{4}$

In the cementation of fiber posts into prepared root canals, the curing light is severely attenuated by the post before it reaches the resin cement. 5,6 Therefore, there are regions at the resin cement layer where curing light is delivered at considerably low intensity to activate photo-sensitive initiators, so the resin cement relies on the self-curing components to ensure optimum polymerization. ${ }^{7}$ Effective polymerization is an important factor closely related to resin cement's mechanical and physical properties, which are crucial to ensure the durability of the post/resin cement/root interface. ${ }^{8}$ However, some studies evaluating the hardness of dual-cured resin cements have shown that the self-curing mode of such products is less effective than the dual-curing mode. ${ }^{7-9}$

Another important issue to consider is the chemical incompatibility between acidic mono- mers from adhesive systems and the self-curing components of dual-cured resin cements due to the low $\mathrm{pH}$ of bonding agents. ${ }^{10,11}$ Previous studies have demonstrated that acidic monomers present in either total etching or self-etching adhesive systems are capable of neutralizing the self-curing components of dual-cured resin cements. ${ }^{12}$ Therefore, no monomer conversion is observed when resin cements in contact with adhesive resins rely solely on the self-curing mode. ${ }^{12}$ For this reason, manufacturers have developed the so-called "dual cure" adhesive systems, in which co-initiators are added to the adhesive resins to avoid the chemical incompatibility between the adhesive system and resin cement. In this condition, the self-curing components can initiate polymerization when light is attenuated due to the presence of an indirect restoration or completely absent at the apical third during post cementation. $4,7,8$ Therefore, the aim of the current study was to evaluate the Vickers hardness (VHN) of dual-cured resin cements after post cementation using self-etching and two-step etchand-rinse adhesive systems. The research hypothesis was that the hardness of resin cements after fiber post cementation is not affected by the adhesive resins applied to the root canal walls.

\section{MATERIALS AND METHODS}

Fifty bovine incisors had their crowns and part of the roots removed to obtain standard roots with $17 \mathrm{~mm}$ length. The root canals had their pulp tissues removed with a second series K-File (Dentsply Maillefer, Ballaigues, Switzerland) and were prepared for post cementation by a \#5 Largo bur (Dentsply Maillefer, Ballaigues, Switzerland) at low speed.

The roots were assigned to five experimental groups ( $n=10$ ) according to the following resin cement products (Table 1 and 2) and curing modes: Prime\&Bond 2.1 Dual Cure and Enforce exposed to curing light (PBDC-LCEN); Prime\&Bond 2.1 and Enforce exposed to curing light (PB- LCEN); Prime\&Bond 2.1 Dual Cure and Enforce without light exposure (PBDC-SCEN); ED Primer and selfcured Panavia 21 (ED-SCPN); Clearfil SE Bond and self-cured Panavia 21 (CF-SCPN). The bonding agents and resin cements were applied to the root dentin walls following the manufacturer's instructions (Table 1). Glass fiber posts (Reforpost, Angelus Dental Industry Products S/A, Londrina, PR, 
Brazil) were cemented into the roots, and the resin cements were light-activated for $40 \mathrm{~s}$ (Power Density: $600 \mathrm{~mW} / \mathrm{cm}^{2}$, Optilight Plus, Gnatus, Ribeirão Preto, Brazil) in the light-cured groups. The roots with cemented posts were stored in distilled water for $72 \mathrm{~h}$ at $37^{\circ} \mathrm{C}$ and then transversely sectioned into 3-mm thick thirds, which were designated as coronal, medium, and apical thirds. The exposed surfaces were wet-ground with 400-, 600-, 1200-, and 2000-grit SiC papers (3M, St Paul, MN, USA). The specimens were dark-stored under dry condition at $37^{\circ} \mathrm{C}$ for $7 \mathrm{~d}$ in an oven to allow complete resin cement polymerization.

The hardness analysis (HMV-2, Shimadzu Co, Kyoto, Japan) was performed with $50 \mathrm{~g}$ load for 30 s. The sectioned surface was virtually divided into quarters, and two indentations were made on the resin cement layer in each quarter: one next to the post and another one next to the dentin wall (Figure 1). The results were expressed in Vickers hardness (VHN).

Statistical analyses were performed by using SAS software version 8.0 for Windows (SAS Institute Inc., Cary, NC, USA). The results were analyzed by three-way repeated measures ANOVA ("product," "root third," and "indentation position" factors) followed by the post-hoc Tukey's test (preset alpha of $5 \%$ ) to detect the differences among groups.

\section{RESULTS}

According to the three-way repeated measures ANOVA test, an interaction was detected between "indentation position" and "product" factors $(P<.05)$, and between "root third" and "product" factors $(P<.05)$. Figure 2 shows the comparison between values from the resin cement near the post and the resin cement near the dentin wall. Based on Tukey's post hoc test, most resin cements presented higher VHN values near the post than near the dentin wall $(P<.001$, Figure 2). The only exception was observed for PBDC-SCEN group, in which no significant difference in VHN values was observed between the resin cement located near the post and that near the dentin wall.

Table 3 shows the comparison of VHN values among products within each root third as well as the comparison of VHN values among root thirds within each product. ED-SCPN showed the highest VHN values regardless of root third and position, while PBDC-SCEN exhibited the lowest values. No significant difference was noted between the light-

Table 1. Composition and manufacturers' instructions of the adhesive systems used in this study.

\begin{tabular}{|c|c|c|}
\hline $\begin{array}{l}\text { Adhesive Systems } \\
\text { (Manufacturer) }\end{array}$ & Composition & Manufacturer's Instructions \\
\hline $\begin{array}{l}\text { Clearfil SE Bond } \\
\text { (Kuraray Co. Ltd. } \\
\text { Osaka, Japan) }\end{array}$ & $\begin{array}{l}\text { SE-Primer: MDP, HEMA, CQ, N,N-Diethanol p- } \\
\text { toluidine, hydrophilic dimethacrylate and water }(\mathrm{pH} \\
\text { = 2). SE-Bond: MDP, Bis-GMA, HEMA, hydrophobic } \\
\text { dimethacrylate, CQ, N,N-Diethanol p-toluidine and } \\
\text { silanated colloidal silica. }\end{array}$ & $\begin{array}{l}\text { Apply PRIMER to the entire cavity wall with a disposable } \\
\text { brush tip. Leave it in place for } 20 \text { seconds. Evaporate the } \\
\text { volatile ingredients with a mild oil-free air stream. Apply } \\
\text { BOND to the entire surface of the cavity with a disposable } \\
\text { brush tip. Create a uniform bond film using a gentle oil-free } \\
\text { air flow. Light-cure the BOND for } 10 \text { seconds with a dental } \\
\text { curing light. }\end{array}$ \\
\hline $\begin{array}{l}\text { Prime and Bond } 2.1 \\
\text { Dual Cure } \\
\text { (Dentsply Caulk, } \\
\text { Milford, DE, USA) }\end{array}$ & $\begin{array}{l}\text { Adhesive: Acetone; Dimethyl Ketone; } 2 \text {-Propanone; } \\
\text { Acrylic Monomer and Elastomer; PENTA, Photoini- } \\
\text { tiators, Stabilizers Cetylamine Hydrofluoride, Ac- } \\
\text { etone. } \\
\text { Activator: Acetone (< than } 65 \% \text { W); Ethyl Alcohol }< \\
\text { than } 45 \% \text { W); Sodium p-Toluenesulfinate. Etchant: } \\
\text { Water, } 34 \% \text { Phosphoric acid, Silicon Dioxide, Sur- } \\
\text { factants, Blue Colorant. }\end{array}$ & $\begin{array}{l}\text { Place 1-2 drops of the adhesive and equal number of drops } \\
\text { of Self-Cure Activator into a mixing well; Mix contents } \\
\text { for } 1-2 \text { seconds with a clean, unused brush tip; Using } \\
\text { the disposable brush supplied, immediately apply mixed } \\
\text { adhesive/activator to thoroughly wet all the tooth surfaces. } \\
\text { These surfaces should remain fully wet for } 20 \text { seconds and } \\
\text { may necessitate additional applications of mixed adhesive/ } \\
\text { activator; Remove excess solvent by gently drying with a } \\
\text { dental syringe for at least } 5 \text { seconds. Surface should have a } \\
\text { uniform glossy appearance. Cure mixed adhesive/activator } \\
\text { for } 10 \text { seconds using a curing light unit. }\end{array}$ \\
\hline $\begin{array}{l}\text { ED Primer } \\
\text { (Kuraray Co. Ltd. } \\
\text { Osaka, Japan) }\end{array}$ & $\begin{array}{l}\text { Primer A: 10-Methacryloyloxydecyl Dihydrogen } \\
\text { Phosphate; Hydroxyethyl Methacrylate, Ethylene } \\
\text { Glycol Methacrylate; N, N-Di-(2-Hydroxyethyl)-P- } \\
\text { Toluidine; N-Methacryloyl 5-Aminosalicylic Acid; } \\
\text { Water. } \\
\text { Primer B: Benzenesulfinic Acid, Sodium Salt; N, } \\
\text { N-Di-(2-Hydroxyethyl)-P-Toluidine; } \\
\text { N-Methacryloyl 5-Aminosalicylic Acid; Water }\end{array}$ & $\begin{array}{l}\text { Dispense one drop each of Liquid A and Liquid B on the } \\
\text { mixing plate and mix. Apply ED PRIMER II to the entire } \\
\text { adherend tooth surface (enamel and dentin), metal, or } \\
\text { composite resin abutment with a small brush or sponge } \\
\text { and leave it in place for } 30 \text { seconds. Using a sponge or } \\
\text { paper point, remove excess primer to prevent the primer } \\
\text { from pooling in the corners of the cavity. Dry the primer } \\
\text { completely by using gentle air flow. Remember that a } \\
\text { pool of the primer will cause quick polymerization of the } \\
\text { adhesive cement. }\end{array}$ \\
\hline
\end{tabular}

PENTA, dipentaerythritol penta acrylate monophosphate; HEMA, 2-Hydroxyethyl Methacrylate; BISGMA, bisphenol-a glycidyldimethacrylate. 
cured groups PBDC-LCEN and PB-LCEN. CFSCPN showed lower VHN values than ED-SCPN in all root thirds and positions.

In terms of the influence of the root third on cement hardness, the resin cements from lightactivated PDDC-LCEN and PB-LCEN groups exhibited lower $\mathrm{VHN}$ values at the apical third than at the coronal third $(P=.0408$ and $P=.0001$, respectively). For PDDC-LCEN and PB-LCEN, no significant difference in resin cement VHN values was noted between the coronal and medium thirds or between the medium and apical thirds. For the self-cured PBDC-SCEN, ED-SCPN, and CF-SCPN groups, no significant difference in resin cement $\mathrm{VHN}$ values was noted among root thirds.

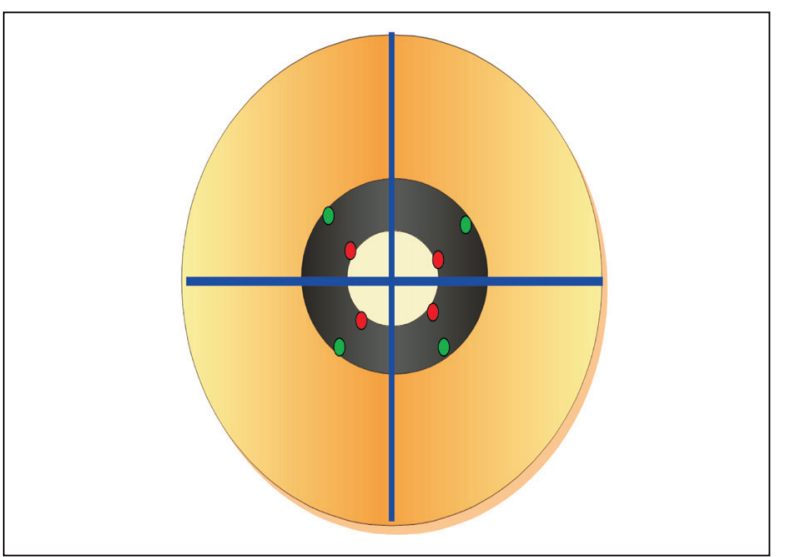

Figure 1. Illustrative image of specimen surface divided into quarters. Orange: root dentin; Dark gray: resin cement layer; Small green circles: indentation next to dentin walls; Small red circles: indentation next to glass fiber post.

Table 2. Composition of the resin cements used in this study.

\begin{tabular}{ll}
\hline Adhesive Systems (Manufacturer) & \multicolumn{1}{c}{ Composition } \\
\hline Panavia 21 & Catalyst paste: 10-Methacryloyloxydecyl dihydrogen phosphate; Hydrophobic aromatic dimethacry- \\
(Kuraray Co. Ltd. Osaka, Japan) & $\begin{array}{l}\text { Base paste: Hydrophobic aromatic dimethacrylate; Hydrophobic aliphatic dimethacrylate; Hydro- } \\
\text { philic aliphatic dimethacrylate; Silanated titanium oxide; Silanated barium glass filler; Catalysts; }\end{array}$ \\
& Accelerators; Pigments; Others. \\
& Base paste: Barium boron fluoroalumino silicate glass, Bis-GMA resin, Polymerizable di- \\
& methacrylate resin; Hydrophobic Amorphous Fumed Silica, Titanium Dioxide, Other. \\
Cnforce & Catalyst paste: colorants are inorganic iron oxides, tertiary amines. Catalyst paste: Barium boron, \\
(Dentsply Caulk, Milford, DE, USA) & fluoroalumino silicate glass, Bis-GMA resin, Polymerizable dimethacrylate resin, Hydrophobic \\
& Amorphous Fumed Silica, Titanium Dioxide, Benzoyl Peroxide
\end{tabular}

BISGMA, bisphenol-a glycidyldimethacrylate.

Table 3. Mean VHN (standard deviation) of all cementing systems at different root thirds.

\begin{tabular}{|c|c|c|c|c|c|}
\hline & $\begin{array}{c}\text { Prime and Bond } 2.1 \\
\text { Dual Cure }\end{array}$ & Prime and Bond 2.1 & $\begin{array}{c}\text { Prime and Bond } 2.1 \\
\text { Dual Cure }\end{array}$ & ED Primer & Clearfil SE Bond \\
\hline & Enforce & Enforce & Self-cured Enforce & Panavia 21 & Panavia 21 \\
\hline Coronal & $52.6(4.4) \mathrm{Ab}$ & 54.1 (3.5) Aab & $41.6(3.2) \mathrm{Ac}$ & $57.6(6.6) \mathrm{Aa}$ & 45.5 (3.3) Ac \\
\hline Medium & $50.7(5.1) \mathrm{ABb}$ & $50.0(3.4) \mathrm{ABb}$ & 41.1 (3.0) Ac & $57.2(5.8) \mathrm{Aa}$ & $46.8(3.0) \mathrm{Ab}$ \\
\hline Appical & $48.1(3.7) \mathrm{Bb}$ & $47.7(3.6) \mathrm{Bb}$ & $41.8(3.1) \mathrm{Ac}$ & 53.5 (4.3) Aa & 44.6 (3.0) Abc \\
\hline
\end{tabular}

Means followed by different letters (comparisons among products were indicated by lower case letters; comparisons among root thirds were indicated by upper case letters within column) are significantly different $\quad(P<.05)$.

DISCUSSION

According to the results of the current study, most resin cements exhibited lower VHN values near the dentin wall than near the post. One could attribute such differences in VHN to the chemical incompatibility for all light-activated groups. However, the lack of significant differences between the cement VHN near the dentin walls and cement $\mathrm{VHN}$ near the post in the self-cured group PBDCSCEN indicates that differences between cement

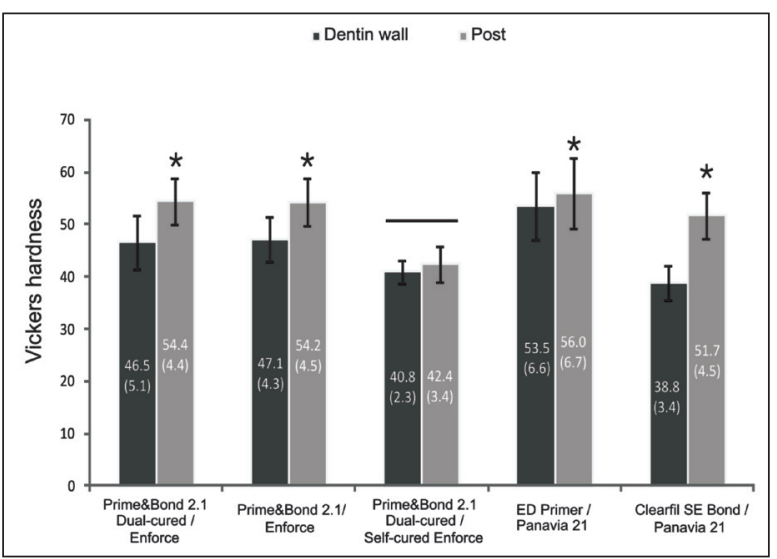

Figure 2. Bar graph showing the mean VHN values of the cement layer close to the for the comprison to dentin wall in all experimental groups. Significant differences near the dentin wall are indicated by asterisk $(*$ : $P<.05)$. Bars connected by line are not significantly different. , 
from other studies, ${ }^{12-14}$ the inclusion of co-initiators to the bonding agents in that group was apparently effective in neutralizing the chemical incompatibility between acidic monomers from the two-step etch-and-rinse bonding agent and the dual-cured resin cement. Therefore, the presence of acidic monomers from the oxygen-inhibited layer did not affect the polymerization of Enforce when co-initiators were used. Thus, the research hypothesis was validated for Prime\&Bond 2.1 / Enforce.

Despite this apparent effectiveness of co-initiators in neutralizing the chemical incompatibility between bonding agent and resin cement, most resin cements exhibited lower VHN values near the dentin wall than near the post. Among the possible reasons to explain such differences in VHN values, one might be related to the curing unit features. According to Price et al, ${ }^{15}$ some curing units do not have uniform radiation across the beam, so many may deliver more energy from the center in comparison to the light delivered from the periphery. Another reason can be attributed to the thick resin cement layer around the fiber posts due to the wider diameter of root canals of bovine incisors in comparison to human incisor roots (Figure 1). In this clinical situation, thick resin cement layers are created around the posts, so curing light is not only attenuated by fiber post ${ }^{5,16}$ but also the resin cement layer around the post. As a consequence, lower energy was delivered near dentin wall than near the post.

Similarly to Enforce, Panavia 21 showed higher VHN values close to the post than close to the dentin wall in the self-cured groups ED Primer/ Panavia 21 and Clearfil SE Bond/Panavia 21. Once the curing light was not involved in the activation of polymerization of Panavia 21, the association between bonding agent and resin cement interfered with the VHN values of the resin cement layer near the dentin wall. Therefore, the research hypothesis was invalidated for these products. After photoactivation of Clearfil SE Bond, a nonpolymerized resin layer with a $\mathrm{pH}$ of $1.35^{17}$ remains on the top of the polymerized adhesive resin layer because of an interaction with oxygen. ${ }^{18,19}$ Such a layer has acidic vinyl monomers with carboxylic or phosphate groups, which interact with binary peroxide-amine catalytic components from the self-cured Panavia 21 as previously demonstrated in other studies. ${ }^{11,12,14}$ As a consequence, Panavia 21 from group CF-SCPN exhibited the lowest VHN values near the dentin wall in contrast to the high VHN values observed near the post.

On the other hand, the use of ED Primer associated with Panavia 21 resulted in higher VHN values than the use of Clearfil SE Bond. Differently from Clearfil SE Bond, ED Primer has T-isopropylic benzenic sodium sulfinate, a co-initiator added to primer liquid B (manufacturer's information). This salt reacts with the acidic resin monomers present in primer $A$ and with the resin cement itself to produce free radicals that can enhance the polymerization reaction. ${ }^{20,21}$ Such results confirmed the importance of ED Primer on the polymerization effectiveness of Panavia 21, despite the low pH of ED Primer. However, it seems that the low pH of ED Primer may still have some detrimental effects on polymerization of Panavia 21, as the VHN values near the dentin wall were lower than those near the post.

With regard to the comparison in VHN values among products, Enforce from the light-activated group without the inclusion of co-initiators (PBLCEN) exhibited higher VHN values at the apical third than Enforce from self-cured group with co-initiators added to the bonding agent (PBDCSCEN). This result was unexpected since the fiber post used in the current study is not capable of transmitting the curing light to the surrounding resinous material at the apical third ${ }^{5,16}$ and the acidic monomers can neutralize the self-curing components when co-initiators are not used along with adhesive systems. ${ }^{11,12,14}$ According to some authors, ${ }^{11,12,14}$ the polymerization initiated by lightactivation is not impaired by the presence of acidic monomers from bonding agents like when polymerization is initiated by self-curing components. Thus, light-activation of Enforce at the coronal third may have somehow contributed to resin cement polymerization at the apical third. Therefore, further studies are required to explore this speculation.

Regardless of the type of adhesive system associated to the resin cement during post cementation, both light-activated groups exhibited significant decrease in cement VHN values from coronal to apical thirds. This result is similar to others $s^{6,22}$ and confirms the deleterious effects of compromised light intensity on resin cement polymer- 
ization 3,7,23-27 and the lower effectiveness of the self-curing mode of dual-cured resin cements in comparison to the light-curing mode. ${ }^{7}$ On the other hand, the some self-cured groups seemed to be more effective than the dual-curing modes of the other materials regarding polymerization uniformity. Based on these findings, clinicians should be aware of not only the possible effects of adhesive systems on hardness uniformity around posts, but also the curing potential of resin cements as well as the total energy delivered to the resin cement before choosing the most appropriate material to cement fiber posts into root canals.

\section{CONCLUSION}

According to the current results, bonding agents might promote changes in hardness uniformity of resin cements after post cementation. However, the effects are product dependent.

\section{REFERENCES}

1. Adanir N, Belli S. Stress analysis of a maxillary central incisor restored with different posts. Eur J Dent 2007;1:67-71.

2. Asmussen E, Peutzfeldt A, Heitmann T. Stiffness, elastic limit, and strength of newer types of endodontic posts. $J$ Dent 1999;27:275-278.

3. el-Badrawy WA, el-Mowafy OM. Chemical versus dual curing of resin inlay cements. J Prosthet Dent 1995;73:515-524.

4. Hofmann N, Papsthart G, Hugo B, Klaiber B. Comparison of photo-activation versus chemical or dual-curing of resinbased luting cements regarding flexural strength, modulus and surface hardness. J Oral Rehabil 2001;28:1022-1028.

5. Goracci C, Corciolani G, Vichi A, Ferrari M. Light-transmitting ability of marketed fiber posts. J Dent Res 2008;87:11221126.

6. Radovic I, Corciolani G, Magni E, Krstanovic G, Pavlovic V, Vulicevic ZR, Ferrari M. Light transmission through fiber post: the effect on adhesion, elastic modulus and hardness of dual-cure resin cement. Dent Mater 2009;25:837-844.

7. Fonseca RG, Cruz CA, Adabo GL. The influence of chemical activation on hardness of dual-curing resin cements. Braz Oral Res 2004;18:228-232.

8. Rueggeberg FA, Caughman WF. The influence of light exposure on polymerization of dual-cure resin cements. Oper Dent 1993;18:48-55.

9. Caughman WF, Chan DC, Rueggeberg FA. Curing potential of dual-polymerizable resin cements in simulated clinical situations. J Prosthet Dent 2001;85:479-484.
10. Franco EB, Lopes LG, D'Alpino PH, Pereira JC. Influence of $\mathrm{pH}$ of different adhesive systems on the polymerization of a chemically cured composite resin. Braz Dent J 2005;16:107111.

11. Sanares AM, Itthagarun A, King NM, Tay FR, Pashley DH. Adverse surface interactions between one-bottle lightcured adhesives and chemical-cured composites. Dent Mater 2001;17:542-556.

12. Arrais CA, Giannini M, Rueggeberg FA. Effect of sodium sulfinate salts on the polymerization characteristics of dual-cured resin cement systems exposed to attenuated light-activation. J Dent 2009;37:219-227.

13. Arrais CA, Rueggeberg FA, Waller JL, de Goes MF, Giannini M. Effect of curing mode on the polymerization characteristics of dual-cured resin cement systems. J Dent 2008;36:418-426.

14. Tay FR, Suh BI, Pashley DH, Prati C, Chuang SF, Li F. Factors contributing to the incompatibility between simplifiedstep adhesives and self-cured or dual-cured composites. Part II. Single-bottle, total-etch adhesive. J Adhes Dent 2003;5:91-105.

15. Price RB, Rueggeberg FA, Labrie D, Felix CM. Irradiance uniformity and distribution from dental light curing units. $J$ Esthet Restor Dent 2010;22:86-101.

16. dos Santos Alves Morgan LF, Peixoto RT, de Castro Albuquerque R, Santos Correa MF, de Abreu Poletto LT, Pinotti MB. Light transmission through a translucent fiber post. $J$ Endod 2008;34:299-302.

17. Schittly E, Bouter D, Le Goff S, Degrange M, Attal JP. Compatibility of five self-etching adhesive systems with two resin luting cements. J Adhes Dent 2010;12:137-142.

18. Rueggeberg FA, Margeson DH. The effect of oxygen inhibition on an unfilled/filled composite system. $J$ Dent Res 1990;69:1652-1658.

19. Ruyter IE. Unpolymerized surface layers on sealants. Acta Odontol Scand 1981;39:27-32.

20. Ikemura K, Endo T. Effect of adhesion of new polymerization initiator systems comprising 5-monosubstituted barbituric acids, sulfinate amides, and ter-butyl peroxymaleic acid in dental adhesive resin. J Appl Polym Sci 1999;72:1655-1668.

21. Imai Y, Kadoma Y, Kojima K, Akimoto T, Ikakura K, Ohta T. Importance of polymerization initiator systems and interfacial initiation of polymerization in adhesive bonding of resin to dentin. J Dent Res 1991;70:1088-1091.

22. Teixeira CS, Silva-Sousa YC, Sousa-Neto MD. Effects of light exposure time on composite resin hardness after root reinforcement using translucent fibre post. $J$ Dent $2008 ; 36: 520-528$ 
23. Blackman R, Barghi N, Duke E. Influence of ceramic thickness on the polymerization of light-cured resin cement. J Prosthet Dent 1990;63:295-300.

24. Consani S, Pereira SB, Sinhoreti MA, Correr Sobrinho L. Effect of the methods of photoactivation and insertion on the hardness of composite resins. Pesqui Odontol Bras 2002;16:355-360.

25. Gaston BA, West LA, Liewehr FR, Fernandes C, Pashley $\mathrm{DH}$. Evaluation of regional bond strength of resin cement to endodontic surfaces. $J$ Endod 2001;27:321-324.

26. Hansen EK, Asmussen E. Correlation between depth of cure and surface hardness of a light-activated resin. Scand $J$ Dent Res 1993;101:62-64.

27. Tsai PC, Meyers IA, Walsh LJ. Depth of cure and surface microhardness of composite resin cured with blue LED curing lights. Dent Mater 2004;20:364-369. 